\title{
Architecture as Adventure: Concept Design for Creative Spaces
}

\author{
Yerianne Christa Haywood, I Gusti Ngurah Antaryama, and Sri Nastiti Nugrahani Ekasiwi \\ Department of Architecture, Institut Teknologi Sepuluh Nopember, Surabaya \\ e-mail: yerianne.Ch@gmail.com
}

\begin{abstract}
Abstrak-The physical environment is considered as one factor which has an influence on individual's creative capacity. While the physical setting may not directly induce one's creativity, its effect on creativity is shown in the way it is perceived and utilized by the individual. Therefore, through subjective experience, the built environment may actively hinder or encourage one's creative capacity. Thus, the design of creative spaces is one of architectural interest to potentially aid creative activities by focusing on the users experience of the physical setting. This paper aims to compose a design concept and criteria to address the needs of creative spaces. The literature review examines perception and experience of the built environment, sensory considerations and creativity. Therefore, a phenomenological study is used to investigate individual's perception and subjective experience of the physical environment during the creative process. The result of this study shows that considering individuals' needs, the design criteria is centered on movement, sensory information and social engagement. The concept derived is based on architecture as 'adventure', since it communicates an experience analogous to the creative process. Features of the concept are then applied to massing and form, social engagement, the natural environment and movement as an eventful experience.
\end{abstract}

Kata Kunci-Creativity, Environment, Experiene, Perception, Phenomenology.

\section{INTRODUCTION}

$\mathrm{T}$ HE physical environment is the ground of all human action and activity in this world. This presupposes that while man operates in day to day life, he is in constant connection and interaction with the physical environment. The point of difference between this and other studies is the consideration of the subjective perception of individuals, to explore how they experience the physical environment during creative activity. The aim of the paper is to produce design criteria based on the results of interviews in order to formulate a design concept for creative spaces. It shows that phenomenological thought and investigation can be used as a tool for arriving at a human-centered design, considering the role of the built environment in human experience and potential influences on human activities.

\section{A. Human Creativity and the Physical Environment}

Studies have shown that two general states of brain activity correlate with the two main processes identified in the creative process. The divergent phase is consistent with more low beta wave activity in the right hemisphere, allowing a receptive state of mind and active imagination. While, in convergent thought, the focused attention required for concentration correlates with high beta wave activity in the left prefrontal cortex [1]. The effects of the physical setting on these brain states are also emphasized as a factor which affects the creative potential [2-3]. One study on creativity suggests that 'architectural settings inspire and constrain behavior and cognition through the affordances they offer', thereby positively or negatively impacting user creativity. The study emphasized the link between physical settings and creativity as embodied, embedded and enactive cognition, proposing that the creative individual is dynamically engaged in the environment [4].

Environments perceived as supportive of creativity are most frequently, visually interesting, presenting multiple choices and experiences, such that featureless environments are less conducive [5] [3]. Conducive settings have free and flexibly organized spaces enabling self-expression; a sense of comfort is gained through coherence and legibility, while challenge is represented by complexity and mystery which excite interest [5] [2]. Sensory aspects such as light, color, sound, and natural elements present dimensions for allowing artistic exploration, stimulating thought and perception, mental clarity, reduced anxiety and mental disinhibition among others [1-2] [6]. Creative spaces should also enhance communication and social interaction because with social engagement ideas are readily formed and developed throughout the thinking process of the entire group [2].

\section{B. Phenomenology in Architectural Thought}

Phenomenological thought gives a description of phenomena as they appear to an experiencer's consciousness in an attempt to arrive at the truth of the phenomena, allowing "a return to concrete, lived human experience in all its richness". Therefore, phenomenological thought represents the consideration of subjectivity as a necessary aspect of experience [7]. Through embodied experience, space is perceived as 'a structured arena for action' filled with practical possibilities which can be used in various ways. According to Hale, Merleau-Ponty also describes the individual self as both dependent on and inseparable from its natural and cultural surroundings [8]. This idea of experience represents a constant 'interplay between perception and action', where the operation of the senses is inherent to bodily experience, and the body is central to the inner world of the individual and the outer world [8].

\section{Human Perception and Sensory Experience}

Human perception is a fixed feature in our awareness of the environment as it facilitates sensations which culminate in a subjective understanding of the external world [9]. Experience and perception are fully embodied functions made possible by bodily presence in space, a construct of 
The $6^{\text {th }}$ International Seminar on Science and Technology (ISST) 2020

July $25^{\text {th }} 2020$, Institut Teknologi Sepuluh Nopember, Surabaya, Indonesia

Table 1.

Awareness in the Perceptual Field for each Creative Domain Studied

\begin{tabular}{|c|c|c|c|c|}
\hline No & PHOTOGRAPHY & MUSIC & FILM \& THEATRE & VISUAL ARTS \\
\hline \multirow{4}{*}{1} & erception of the physical setting & & & \\
\hline & $\begin{array}{l}\text { Seeking opportunities and } \\
\text { affordances in the situation of } \\
\text { the shoot. }\end{array}$ & $\begin{array}{l}\text { Seeking opportunities and } \\
\text { affordances in the musical } \\
\text { composition. }\end{array}$ & $\begin{array}{l}\text { Seeking opportunities and } \\
\text { affordances in the forms and } \\
\text { compositions \& human } \\
\text { activity }\end{array}$ & $\begin{array}{l}\text { Seeking opportunities and } \\
\text { affordances in the physical or } \\
\text { social context }\end{array}$ \\
\hline & $\begin{array}{l}\text { Assessing the composition of } \\
\text { the shoot; lighting, color, } \\
\text { shapes, forms, people, etc. }\end{array}$ & $\begin{array}{l}\text { Assessing components of music, } \\
\text { lyrically (in socio-cultural issues) } \\
\text { and as a source of melodies. }\end{array}$ & \begin{tabular}{l} 
Assessing \\
interaction, and \\
cultural issues $\begin{array}{r}\text { socio- } \\
\text { for }\end{array}$ \\
opportunities to create \\
\multicolumn{2}{l}{ stories and produce films. }
\end{tabular} & $\begin{array}{l}\text { Assessing human situations and } \\
\text { socio-cultural issues as a source } \\
\text { of artistic expression, also for } \\
\text { compositions. }\end{array}$ \\
\hline & $\begin{array}{l}\text { Perception of people } \\
\text { For their materiality and } \\
\text { physicality, or as source of } \\
\text { information relating to the } \\
\text { shoot. }\end{array}$ & $\begin{array}{l}\text { As s source of social or cultural } \\
\text { information used as a lyrical basis, } \\
\text { or as source of information } \\
\text { relating to the melody. }\end{array}$ & $\begin{array}{l}\text { Seen materially in relation } \\
\text { to other physical elements } \\
\text { and for the situations they } \\
\text { partake in. }\end{array}$ & $\begin{array}{l}\text { Seen materially in relation to } \\
\text { other physical elements and as } \\
\text { sources of information in the } \\
\text { setting or the project at hand. }\end{array}$ \\
\hline 2 & $\begin{array}{l}\text { High degrees of sensory } \\
\text { information are not perceived as } \\
\text { distracting, but possibly } \\
\text { stimulating. }\end{array}$ & $\begin{array}{l}\text { High degrees of sensory } \\
\text { information are not perceived as } \\
\text { distracting, but possibly } \\
\text { stimulating, particularly in the } \\
\text { aural environment. }\end{array}$ & $\begin{array}{l}\text { High degrees of sensory } \\
\text { information are not } \\
\text { perceived as distracting, but } \\
\text { possibly stimulating. }\end{array}$ & $\begin{array}{l}\text { High degrees of sensory } \\
\text { information are not perceived as } \\
\text { distracting, but possibly } \\
\text { stimulating. }\end{array}$ \\
\hline
\end{tabular}

Perceptual awareness is actively transitioned as more attentive and thought oriented tasks of the creative activity is sought, the individual

3 seeks out a different quality of environment.

Perception of the physical setting for use, to aid in the developmental stages of the process, it is no longer static, but is adaptive and can be reconfigured to allow specific activities and demanding tasks.

Perception of people

4 Interaction with people is sought particularly for evaluative feedback, people are seen as sources of information, functional to the activity at hand, otherwise they may also qualify as distractions. As such the individuals prefer to be selective of social encounters. Sensory Perception \& Preference

5 High degrees of sensory information, in particular, sound and movement (people or large objects) in the visual field are distracting to individuals

Ambient, particularly the aural Ambience in all dimensions. The environment (rhythmic).

6

Light is needed to facilitate some activities aural environment should present no other information besides that which is necessary to the task at hand.

Movement in the visual field is generally less distracting as for other individuals
Ambience; for writing and editing.

For shooting, the physical setting is especially manipulated for the needs of the activity.
Ambience in all dimensions. Light is utilized based on the needs of the activity at hand.

The aural environment is rhythmic with minimal sensory information. which the mind cannot operate without [10]. The field of experience, in which exists sensory information is further described by Aron Gurswitch, and three types of attention and awareness which make up the perceptual field are identified [11]. These are, the central theme, the thematic field and marginal consciousness. The subject of focal attention called the theme, emerges from a 'field', within this total field is a transitive thematic field in which fits the context of theme. He suggests that a 'given theme cannot appear in just any context', but it must be relevant to that context and otherwise recedes into the "margin" of the field becoming irrelevant. However, irrelevant elements retain organizational qualities and may become thematic in later moments.

During perception of the environment, architectural elements are perceived in a "state of habitual distraction", if perceived as functional to a specific objective attention is jolted into intentional focus [12]. Rasmussen in Experiencing Architecture, also states that individuals do not readily see a full image of an object including all details, unless interest is present, while the image seen is predominantly an impression of the thing itself [13]. This is essentially done through inference and holistic perception, even before grasping details of the atmosphere, such that mental constructs are based on the generalizations made from information received
[9] [14]. Thus, our normal state of perception and experiences are based on shifting types of attention anticipated through vision and movement. Rasmussen affirms that an architecture which takes into consideration all of the senses can greatly enhance the experiential quality of the building, since the building itself, with all of it elements and characteristics is the medium for experience [13].

\section{METHOD}

The premise of subjective experience assimilated in this study dictates the use of qualitative research strategies. The phenomenological method of research and analysis by Clark E. Moustakas is used to gather insight from creative individuals through conversational interviews [1]. Giving a narrative-like description of their lived experience during the creative process, individuals are asked to describe their perceived physical settings. The method used involves reduction, filtering of information and deriving meanings to highlight underlying factors that account for what is being experienced. Sensory cues are discussed with consideration of the perceptual field as described by Gurswitch , in order to see the degree of perceptual awareness of the physical setting during each stage of the process [2]. This positions the stages 


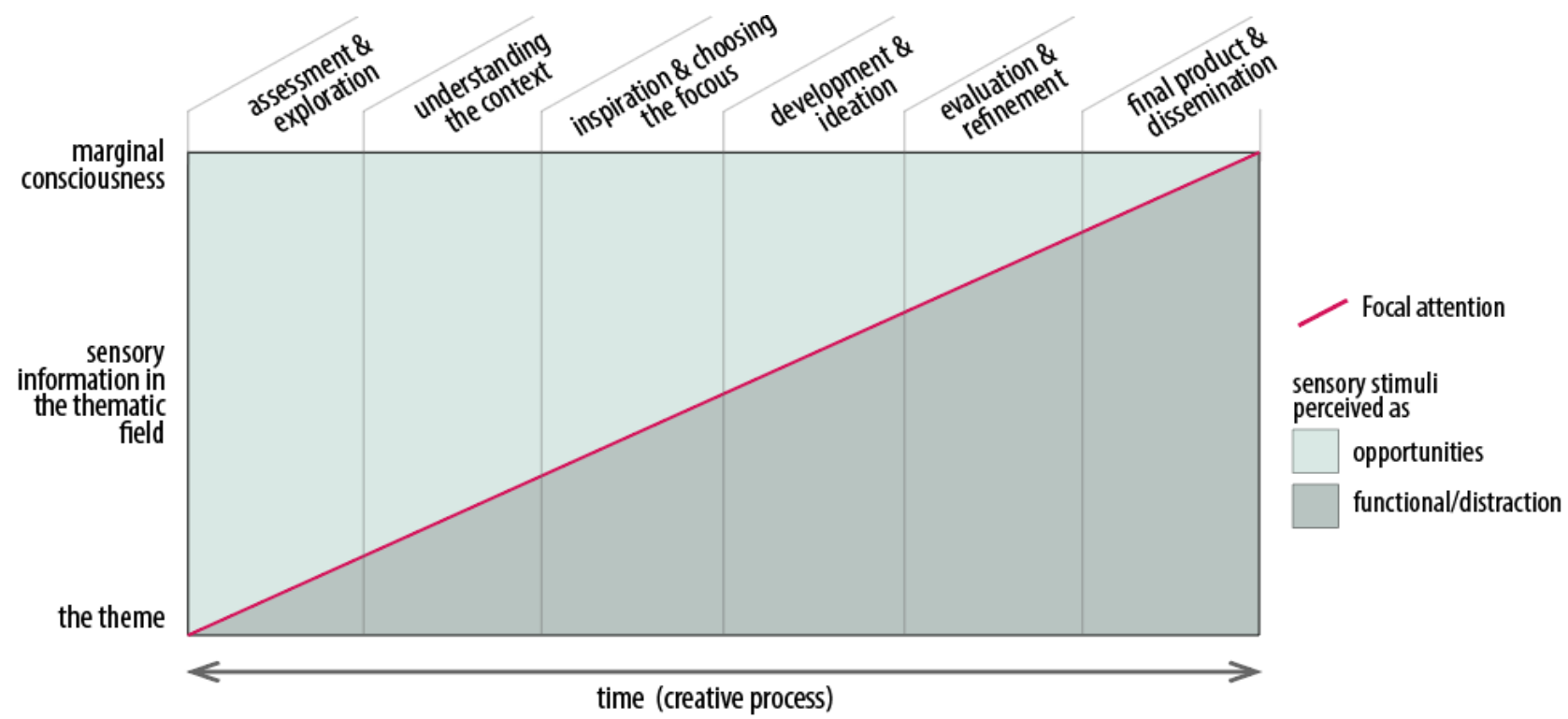

Figure 1. The creative process in Relation to Focal Attention and type of Awareness.

of the creative process in the context of preferred features of physical settings.

The information derived from the study is then utilized to form the basic idea of the design concept. The development of the design concept is based on the concept-based framework described by Plowright [15]. The results of the study as well as components of the design problem are used to formulate a hypothesis as the basis of the design. This hypothesis will be refined to formulate certain design criteria which define the design concept.

\section{RESULT AND DISCUSSION}

\section{A. Analysis of Interviews}

The results of the investigation begin with a representation of the general creative process and the experience of the creative individuals based on their perceptual view of the physical setting. The perception of the physical environment is considered relative to the creative process in each creative domain. The stages of the process in each domain and the perception of the physical setting is represented by the Table 1 , while a summary of the process of creativity relative to different types of attention and awareness is shown in Figure 1 .

\section{1) Exploring the context, needs and limitations}

The first stage of the creative process includes exploration, assessment and even analysis of the context, situation or presented problem space. The problem space varies, though, in each situation the initial perception of the environment seems to be centered on communicating human values based on the intention of the final product. These range from themes, issues to be represented, feelings to be evoked, or human experiences to be extracted. The working context of the problem space, then, appears to be perceived objectively as a resource necessary to facilitate the process. Focal attention is directed to its exploration in order to understand the limitations or opportunities embedded in the particular situation, which also varies among creative domains.

\section{2) Assessing the context, seeking opportunities/affordances}

The need of social interactions in these initial phases is a commonality which acts as a source of information, either, derived from observation of people, or directly, by interaction among people. With consideration to the intended outcome, the affordances of the presented physical setting are then assessed for potential ways of achieving the intended product. Therefore, the physical environment itself is not particularly seen as place for general exploration, but is predominantly taken as it is, to facilitate a contextual assessment. In these initial stages, focal attention is distributed towards the overall physical environment and, perceived sensory input is at a peak to facilitate assessment.

\section{3) Choosing the main focus of the activity (or} unconsciously; 'inspiration')

This is followed by a phase where intangible values are combined with affordances given by the physical context. Past experiences, current knowledge of the domain-based elements, tools and techniques are also utilized in this stage. Through a process chiefly described as mental and internal by creators, ideas are formed through thought associations of the intended product, affordances of the physical setting or context, existing knowledge, and embodied experiences. Any of these factors may instantaneously become a mental trigger that activates other connected thoughts, which culminates in 'inspiration' and points to the focus. Creativity itself appears to be identified with this point of connection and formation of a coherent idea. This phase is very mental and generally takes place in any type of physical setting.

\section{4) Development of ideas}

When the main focus is selected, the creator seeks to use knowledge, tools and experience by exploiting and manipulating the physical setting to externalize the ideas brought forth from inspiration. The physical setting is no longer perceived as particularly static or completely objective, but becomes malleable and able to be configured 
The $6^{\text {th }}$ International Seminar on Science and Technology (ISST) 2020

July $25^{\text {th }}$ 2020, Institut Teknologi Sepuluh Nopember, Surabaya, Indonesia

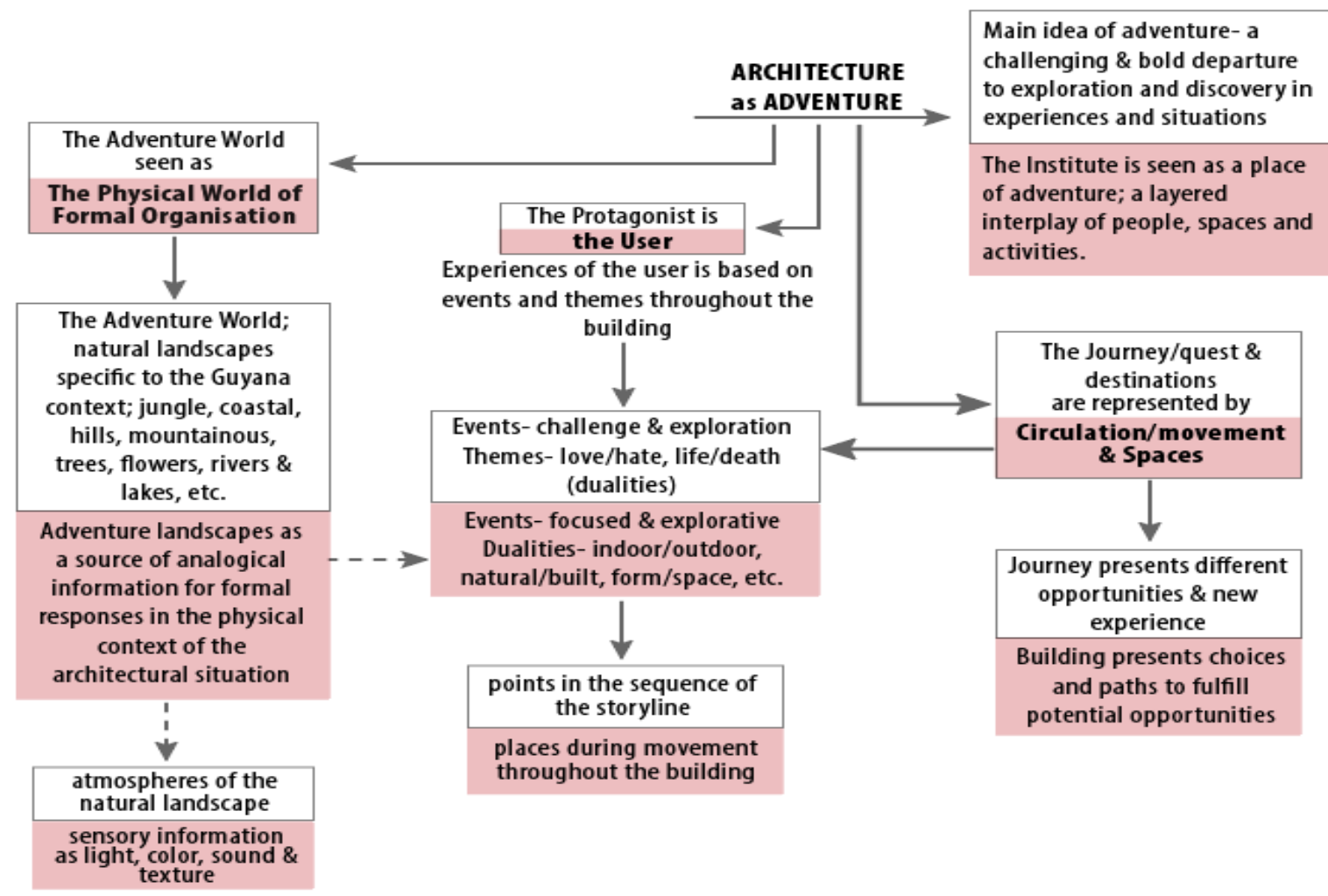

Figure 2. Concepts and Relationships of Adventure transferred to the Domain of Architecture.

and adjusted as the creator needs. Perceptual awareness of the environment is heightened so as to determine the use of physical elements and quality of atmosphere which encourage or hinder further development and refinement of ideas.

\section{5) Refinement through evaluation}

The quality of environment perceived during the initial phase of the process is intentionally adjusted to suit the state of mind required for further development of the creative endeavor. Sensory cues are now particularly monitored and kept at minimum, towards the further margins of the perceptual field. At this point, prominent sensory information of any nature, which challenge focal attention and do not contribute to development may be deemed as distractions; as a result, isolation is preferred. this is also related to the need of comfort mentioned as one aspect seen chiefly throughout the latter phases of the creative process. The presence of discomfort is one aspect which may also hinder creativity since it draws the attention to its source and therefore qualifies as a distraction. This shows that as the creator becomes more intentional and selective, the focal attention gradually intensifies to the task at hand. While focus and concentration are increased, the individual's sensitivity towards sensory stimuli also increases, thereby requiring lower levels of stimuli.

\section{6) Final production and dissemination}

In the final stages of creativity, the creative product has been completed and given to an audience for viewing. During dissemination, the viewer's focus and concentration is intensified, all focal attention is directed to the creative production. And, sensory information in the perceptual field unrelated to the object or, which diverts attention is seen as a distraction.

Having differentiated between two general types of physical settings which facilitate the process, it is not reasonable to suggest that either of the two physical settings described above, would be entirely conducive to the creative process. It can be inferred that the two ways in which the physical setting and associated sensory information is perceived, actually vary in intensity and are correlated. The awareness and perception of the physical setting and the choice of setting as the thematic field is dependent on the stage of the process and the activities done within. Figure 1 represents the perception of the physical environment, whereby, as the creative process progresses focal attention increases. The physical setting perceived as a source of opportunity decreases and the potential for sensory distractions increase.

\section{B. Criteria for Design}

Use SI unit or SI derived units. The major themes found in the above analysis of the interviews conducted are based on the way the environment is utilized for the various tasks involved in creative endeavors. The first theme is the need for exploration to solicit information which will be used to develop ideas for the creative activity. We see then, that, in order for exploration to be fulfilled, there must be the presence of opportunities relative to elements of the creative domains. The second theme is the evaluation which feeds the development of ideas and progression of the work. Here, instead of soliciting information, the individual is creating mental information for the task at hand, which can be conveyed as challenge. The following aspects of design 
The $6^{\text {th }}$ International Seminar on Science and Technology (ISST) 2020

July $25^{\text {th }} 2020$, Institut Teknologi Sepuluh Nopember, Surabaya, Indonesia

which are most essentially connected with the creative process are further addressed below with consideration to exploration and challenge as evaluation.

\section{1) Movement and Access/Use}

One of the essential aspects of importance from the information gathered above is movement as form of agency, to create access to different functions, activities and spaces. This is critical in the initial phases since it allows for exploration and seeking new insights or potentialities which may be useful to the creative endeavor. The soliciting of information from the environment presents the individual with potentialities as opportunities for action or lines of inquiry. The opportunities found during the initial stages can be directly related to the explorative features of creativity. They represent the potential engagement with new experiences, which may be unplanned social encounters, new perspectives on different creative domains or moments of insight from external stimuli. However, these opportunities ultimately lead to the following stages of the process.

Movement facilitates the ability to choose less explorative spaces, enabling the mental and physical transitions to other parts of the creative process involving more focused attention. While less information is solicited from the environment, the individual seeks to explicate the mental ideas formed in imagination for the creative endeavor. This is fulfilled when the individual chooses a space, or reconfigures a space to be conducive to the desired activity. Therefore, flexibility is a key aspect of the functional space.

The creative spaces which are given access fit into the two categories of the explorative and challenging nature of the creative process. The distinction of these types of spaces and those within the spectrum is particularly based on the quality of the atmosphere. This points to sensory aspects of the space, including light, color, sound, etc., and even the presence of opportunities for social engagement. The movement and access to spaces will therefore become the foundation for sensory considerations. Additionally, it can also dictate the general form and massing of the building, after considerations of the environmental context is examined.

\section{2) Sensory Delight}

The sensory information relative to the aesthetic view of architectural elements, predominantly color and materiality, are not particularly mentioned as a major aspect of individual's focal attention. However, in as much as it is relative to the creative domain, such as visual arts and photography, they play an important role in the perceptual field. The use of color in the environment can be seen as a source of information to be solicited for intentional use by the creative individual, or simply for aesthetic pleasure. Further, color as a way of communication to facilitate and simplify the interaction of the user with the building. In this sense, color can be used as identification or distinction which communicates different uses and activities grounding the place, thereby making it functional.

The presence of light allows the color to be seen and to some extent influences the kind of experience associated. Light, is particularly seen for its highly functional uses in facilitating certain tasks, such as required by photography, visual arts and film. The type of lighting to be used, whether colored, daylight or white fluorescent light is based on the activity type. Such as daylighting preferences for making details, or colored lights for creating an atmosphere of entertainment. Color and light should be combined to fulfil the aforementioned ways by which color is potentially employed. This perception is also influenced by normative theory on the general perception of colors and associated effects. Further, culture and social norm will dictate the use of particular colors in the environment, depending on the meaning and symbolism associated.

\section{3) Social Engagement}

Human interaction is essential throughout the creative process, and like previously discussed themes, it is perceived relative to the activities done in the creative endeavor. Within the explorative feature of the initial stages social engagement represents a source of context for deriving cultural symbolism or meaning. This information could be metaphorically transferred in the creative productions. Secondly, the next perceptual understanding is based on the physicality and materiality of the form, position and arrangement of social interactions, to be used in the technical production of the creation.

On the other hand, these two qualities are also reflected in the evaluative aspect of the process. Where in refinement, the social interaction sought, is contextually dependent on information directly related to some aspect of the creative production, as in feedback for development. And, secondly, the materiality and physicality of the perception of human presence in the latter stages of the process are seen where social interactions become a source of distractions. Here, people are perceived as sources of sensory information and interaction is limited to fulfil the necessary degree of sensory stimulation needed.

\section{The Hypothesis: Architecture as Adventure}

These themes mentioned above, reflect criteria to be fulfilled by the design concept which is derived through questioning, to arrive at an initial idea, and further, the hypothesis and concept. The hypothesis developed as the foundation of the concept is 'architecture as adventure'. The idea of dreams is selected as this starting point, since it is similarly relative to the subjective experience and neurological processes evident in the creative process. Further, many studies show the connection between dreaming and creativity and the roles each play in this connection. Adventure is seen as a chief feature, derived from deeper examination of the nature of dreams and dreaming, having a root in themes of mystery and puzzle or discovery. Additional inquiries of the idea of adventure shows that exploration and evaluation are major themes reflected in what is conveyed in the meaning of adventure.

Thus, the concept of adventure is chosen as a concept which embodies the nature of creative work, also having a physical departure to architectural syntax. Explorative and evaluative techniques of questioning are used for identifying elements and relationships active in the concept of adventure using both literature and film for metaphoric or analogical information. From the question, 'what is adventure?, three 
The $6^{\text {th }}$ International Seminar on Science and Technology (ISST) 2020

July $25^{\text {th }} 2020$, Institut Teknologi Sepuluh Nopember, Surabaya, Indonesia

main components are identified as, the main character, the journey itself and the adventure world. The information given below is taken from various sources which describe the constituent parts of an adventure [16-18]

\section{1) The Main Character}

This is the individual who goes on the journey of the adventure and is represented by the protagonist. The individual's experience is marked by embarking on an exploration of a generally new world, which leads to many paths of which only one would be followed. The experiences in the adventure most particularly involve challenging situations, in the form of surprises, new experiences and discovery. The adventure presents the opportunity of learning and growth to the protagonist.

\section{2) The Journey/Quest}

The journey in the adventure is represented by a storyline. The storyline is generally a sequential series of climactic/thrilling events, and is directed by the choices of the character. Therefore, the journey presented by the storyline has many paths which lead to various situations and destinations. At many times during the journey, the character is presented with choices which will ultimately direct the storyline of the journey. Another aspect of the journey is the existence of themes, which give the defining characteristics of events which occur along the journey. Theme which define all adventures includes aspects of challenge and exploration, suspense, mystery, unknowns, dilemma, opportunity and change. Challenges faced are personal, external, natural or ethical, etc. However, other themes express dualities such as love \& hate, trust \& betrayal, joy \& sadness, etc., which describe circumstances that face the character. A theme may also identify the general nature of the entire adventure, such as sci-fi, fantasy, dystopian, etc.

\section{3) The Adventure World}

The adventure world is a representation of a fantastical/supernatural version of perceived physical reality, with full sensory experience provided by various places and landscapes which may be real or imagined. The landscapes range from open plains, mountainous areas, jungles, oceans and rivers which appear in various places along the journey. The places where the character experiences events or must journey through are destinations. These destinations are places such as communities and settlements, which have various densities of people, languages, etc. In the exploration of the concept of adventure, various aspects such as, the goal of the adventure, its characteristics and structure, are similar in nature to the creative process of creative individuals. By thinking/questioning of the creative process of individuals as an 'adventure' the proposal can be viewed in terms of architecture as 'adventure'. Therefore, the creative institute is seen as a place of adventure, having a layered interplay of people, spaces and activities.

\section{From Adventure to Architecture Syntax}

The information given above is used to frame the design situation, as a way to see creative spaces and give a perspective on how they can be approached in design. These features are transferred to architectural language, in order that they may be applied to the physical context of the design situation. The response to the design situation is centered on the perception and experience of the user; therefore, the main character of the adventure is seen as the potential users of the institute. Next, the journey of the adventure is perceived as movement and circulation throughout the building, by considering the sequential flow of the storyline. Finally, the adventure world is considered as the main source of tangible information to be used analogically in the ideation of concrete elements for the design. The feature of the adventure world is reflected in the use of 'landscapes' or aspects of the physical world, limited to the context of the selected location of design proposal. These themes are represented in Figure 2, where the highlighted boxes represent the concepts as seen in the domain of architecture. The conceptual response to elements within architectural syntax are further discussed under the topics of (1) Circulation and Use of Space; (2) Massing and Form; and (3) Sensory Information. The design response would consider these conceptual applications relative to the various contexts in the chosen location of the design proposal. Concepts and Relationships of Adventure transferred to the Domain of Architecture can see Figure 2.

\section{1) Circulation and Use of Space}

Criteria regarding the experience of space in settings conducive to creativity suggest exploration and the presence of opportunities as important factors. From the concept of adventure, the paths of the 'journey' are reflected in the movement of the user through parts of the building. The main functional spaces of the institute are seen as various destinations in a journey, and paths to these destinations determine the circulatory system of the building.

The need for opportunity and the ability to choose can be reflected in the idea of bifurcation, which is physically represented by a fork in a path leading to two separate destinations; such that multiple bifurcations would represent access to more places. Paths having multiple bifurcations both vertically and horizontally can therefore provide options for movement between spaces, giving the user the perception of being able to choose and the presence of multiple opportunities. Therefore, the concept of bifurcation can be used as the starting point to derive scenarios for circulation on site and in the building, creating the foundation for social engagement. This would also be reflected in the layout of the building's spaces and functional areas. The relationship between circulation, use of space and a derivative form for the building can be implemented using existing nature as a tangible source in the concept for seeking natural occurences of bifurcation (example, plants \& trees, rivers, etc.) .

\section{2) Massing and Form}

With consideration to the access and connectivity portrayed in the circulation and use of space patterns, the idea of adventure is further revisited to align with deriving the massing and form of the building. In addition to the idea of bifurcation which influences the layout of the building, the massing and form is also infuenced by the experience dictated by adventure. Such that the building metaphorically reflects the experiential notions of adventure, through qualities of boldness, daring and challenge in its form and mass. The 
adventure world, as limtied by the chosen geographical location, is again used as a source for seeking tangible scenarios which reflect these qualities. These qualties are therefore reflected in the architectural elements, such as intense and salient forms, in the shapes used to derive the form of the building.

The design of the building's façade is also based on the geographic features of the locational context. By using the technique of accident and the unconscious, a visual image of the façade's potential design can be developed. The architectural context of the area along with the landscape can be combined to define the façade of the buidling. This would determine materials, colors and texture all relative to the context, while adding a unique approach to the massing of the building, because of the diversity in the forms of landscape. Thus communicating the contextual understanding of the form, color, etc., while the concept is implemented.

\section{3) Sensory information and Social Engagement}

In relation to sensory considerations for the building, the intensity of sensory stimuli is managed depending on the activities done in the spaces, whether for exploratory of evaluative needs. The degree of sensory stimulation can be controlled to some extent, so that over stimulation does not occur in places of highly functional activities, or vice versa; under stimulation in places of exploration. This approach reflects the two ends of the spectrum of sensory stimulation, where higher levels of sensory information are associated with spaces for the explorative phase of creativity, while lower levels of stimulation are identified with spaces where high degrees of focus and concentration are necessary. The perception and experience of sensory information in the building not only reflects the quality of the creative spaces, can also be used for communication and identification of the use of the space. This applies particularly to the indoor environment of the creative space. The primary source of sensory information for human perception is based in the visual field and so color, light, texture and sound are combined.

The external and natural environment offers an suitable opportunity for implementing the adventurous feature in the creative space. Most importantly, the aspect of social engagement can be integated into the natural environment, to create experiences fulfilling to freedom and curious exploration amoung users. It can be used to convey feelings and experiences of playful delight, since the natural environment is a rich source of sensory information. In order to foster social engagement, spaces can be designed for planned social meetings. In these cases the forms of seating elements to be used can be derived from the concept's adventure world, which is contextual to the chosen location. Therefore, the places for seating and social encounters whether planned or unplanned would offer diverse choices in opportunities. Natural vegetation such as trees, shrubs or bodies of water can be weaved in and between these spaces to contribute to the overall experience of adventure, adding complexity to the outdoor space.

\section{CONCLUSION}

This study has found a few themes which are relevant to the design of creative spaces. According to the results of the study these criteria include movement and access, sensory information and social engagement. Each of these are required at varying degrees during the progession of the design process, as they are manifested in both exploratory and evaluative stages of the process. The results also show that, for creative spaces to be optimal, they mus provide spaces which fit between these extremes. The abilitiy to chose in the opportunities presented, whether in the form of spaces, sensory information or social engagement influences the user's experience of freedom and flexibility.

The use of adventure as a conceptual approach, presents opportunities for integrating not only physical analogies directly from the idea of the adventure world, but also prefaces the experience of adventure in the building through metaphoric applications. Therefore, the ideas of exploration and evaluation as seen in the creative process itself can be composed, since the key aspects of the creative process are similarly relevant in the world of adventure experiences. Thus, the application of the concept is able to meet the requirements of the design criteria.

\section{ACKNOWLEDGEMENTS}

This research has been supported by the lecturers and advisors of the Department of Architecture, ITS, who have provide insight and great knowledge in this research. Gratitude is also expressed to the volunteering individuals from the various creative domains, who give insight and participated in the study; and further thanks is extended to all who provided resources and assistance during the course of this study

\section{REFERENCES}

[1] S. Carson, Your Creative Brain, San Fransisco: Jossey-Bass, 2010.

[2] N. Bagheri and S. AliNouri, "The Role of the Physical Environment in the Creative Space of Architecture," Internationl Journal of Humanities and Cultural Studies, vol. 2, no. 4, 2015.

[3] G. J. Puccio and J. F. Cabra, "Organizational Creativity," in The Cambridge Handbook of Creativity, J. C. Kaufman and R. J. Sternberg, Eds., New York, Cambridge University Press, 2010, pp. 145 - 173.

[4] L. H. Malinin, "Creative Practices Embodied, Embedded, and Enacted in Architectural Setting: Toward an Ecological Model of Creativity," Frontiers in Psychology, vol. 6, no. 1978, January 2016.

[5] G. W. Evans and J. McCoy, "The Potential Role of the Physical Environment in Fostering Creativity," Creativity Research Journal, vol. 13, no. 3-4, pp. 409-426, 2010.

[6] M. Tian, "How The Environment Impacts Creative Thinking," 13 January 2014.2 [Online]. Available: http://knowledge.ckgsb.edu.cn/2014/01/13/management/how-theenvironment-impacts-creative-thinking/. [Accessed 2019].

[7] D. Moran, Introduction to Phenomenology, Taylor \& Francis eLibrary: Routledge, 2002.

[8] J. A. Hale, Merleau-Ponty for Architects, New York: Routledge, 2017.

[9] J. M. Malnar and F. Vodvarka, Sensory Design, Minneapolis: University of Minnesota Press, 2004.

[10] H. F. Mallgrave, The Architect's Brain. Neuroscience, Creativity \& Architecture, United Kingdom: Wiley-Blackwell, 2010. 
The $6^{\text {th }}$ International Seminar on Science and Technology (ISST) 2020

July $25^{\text {th }} 2020$, Institut Teknologi Sepuluh Nopember, Surabaya, Indonesia

[11] Gurwitsch, The Collected Works of Aron Gurwitch (1901-1973), vol. 3, R. M. Zaner and L. Embree, Eds., London: Springer Science+Business Media B.V., 2010.

[12] P. Bader, "A Model for Everyday Experience of the Built Environment: the embodied perception of architecture," The Journal of Architecture, pp. 37-41, 2015.

[13] S. E. Rasmussen, Experiencing Architecture, Cambridge: The MIT Press, 1962.

[14] J. Pallasmaa, "Space, Place, Atmosphere: Peripheral Perception in Existential Experience," in Architectural Atmospheres: On the Experience and Poltics of Architecture, Basel, Switzerland, Birkhauser, 2014, pp. $18-41$.
[15] P. D. Plowright, Revealing Architectural Design: Methods, Frameworks and Tools, New York: Routledge, 2014.

[16] T. Gardener, "Seattlepi," Hearst Newspapers, NA. [Online]. Available: https://education.seattlepi.com/characteristics-adventure-fiction6640.html. [Accessed 21 May 2020].

[17] L. J. Erickson, "5 Elements of a Good Adventure Novel," 2015. [Online]. Available: http://leifericksonwriting.com/5-elements-of-agood-adventure-novel/. [Accessed 21 May 2020].

[18] MasterClass, "How to Write an Adventure Story," 8 January 2020 [Online]. Available: https://www.masterclass.com/articles/how-towrite-an-adventure-story\#10-tips-for-writing-an-adventure-story. [Accessed 21 May 2020]. 